\title{
Research on the Improvement Strategy of Express Service Quality Based on Six Sigma Method
}

\author{
Mengxiong Cheng \\ Department of Logistics Engineering, Beijing Wuzi University, Beijing, China
}

\section{Email address:}

15972129158@163.com

\section{To cite this article:}

Mengxiong Cheng. Research on the Improvement Strategy of Express Service Quality Based on Six Sigma Method. American Journal of Theoretical and Applied Business. Vol. 4, No. 1, 2018, pp. 27-36. doi: 10.11648/j.ajtab.20180401.14

Received: March 14, 2018; Accepted: March 29, 2018; Published: May 7, 2018

\begin{abstract}
The promotion of service quality is an important way to increase the popularity of consumers, enhance the competitiveness of enterprises, improve customer loyalty and support the development of e-commerce. It is also the most important issue for current express delivery enterprises and it needs to be solved. Based on the DMAIC analysis process of Six Sigma, this paper selects some enterprises which apply ideas of Lean Production principles and Six Sigma to improve tools by the case study method. This paper aims to provide corresponding improvement strategies, the control methods of overall process and some guidance for China express delivery enterprises which make use of the Six Sigma method. The improvement strategy is to formulate the solution to the express surge; improve the cooperation mechanism of land and air transport; Enhance staff service quality awareness; optimize the workplace environment; accelerating the transformation and upgrading of infrastructure; improve the overall service quality level of the enterprise; the whole process control method is to re-measure the system analysis; re-evaluate the process capability of the focus process; Develop and strictly implement process control plan.
\end{abstract}

Keywords: Six Sigma, DMAIC, Express Delivery Enterprises

\section{Introduction}

In recent years, the express delivery industry in accordance with the structure to promote the supply side of the main line of reform, adhere to innovation and lead, adhere to the people's livelihood, take the initiative to adapt to the new economic development, to achieve sustained and rapid development. Express industry's total business volume exceeded 30 billion, business income close to 400 billion yuan, 2012-2016 express delivery business and business income trends are shown in Figure 1 and Figure 2, respectively.

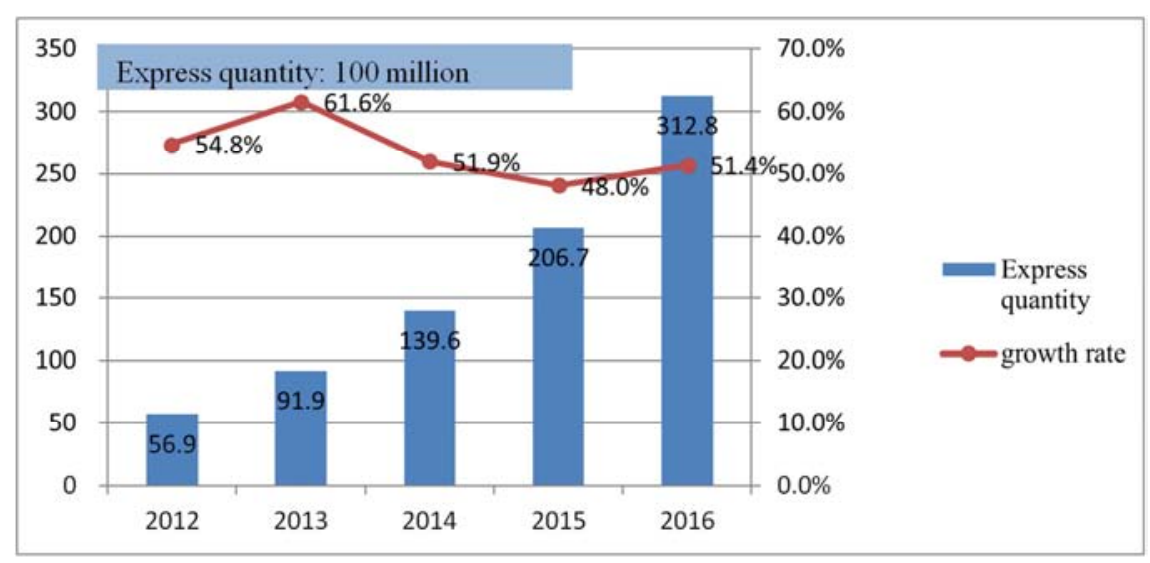

Source: National Post Office

Figure 1. 2012-2016 Express traffic volume. 


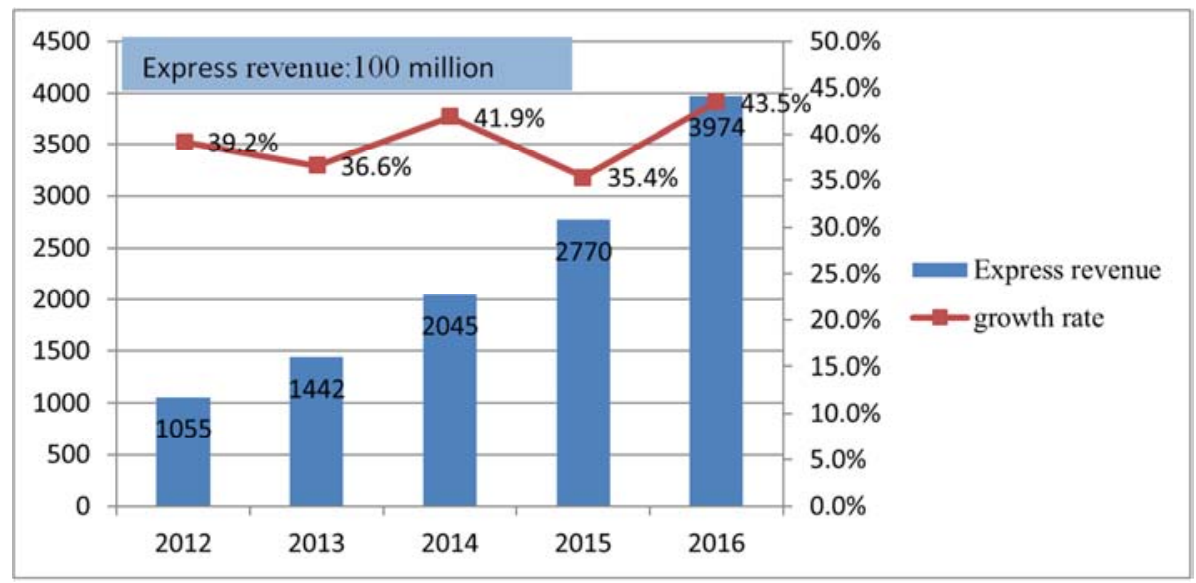

Source: National Post Office

Figure 2. 2012 - 2016 Express business income.

From figure 1 and figure 2 it can see that the courier revenue in 2012 is only 105.5 billion yuan, 2016 annual courier revenue of 397.4 billion yuan, an increase of 43.5\%, 2012 annual business volume of 3.8 times; China's express delivery volume from 5.19 billion in 2012 to 20.16 billion in 2016, the rapid growth of the express business momentum, the increase is considerable.

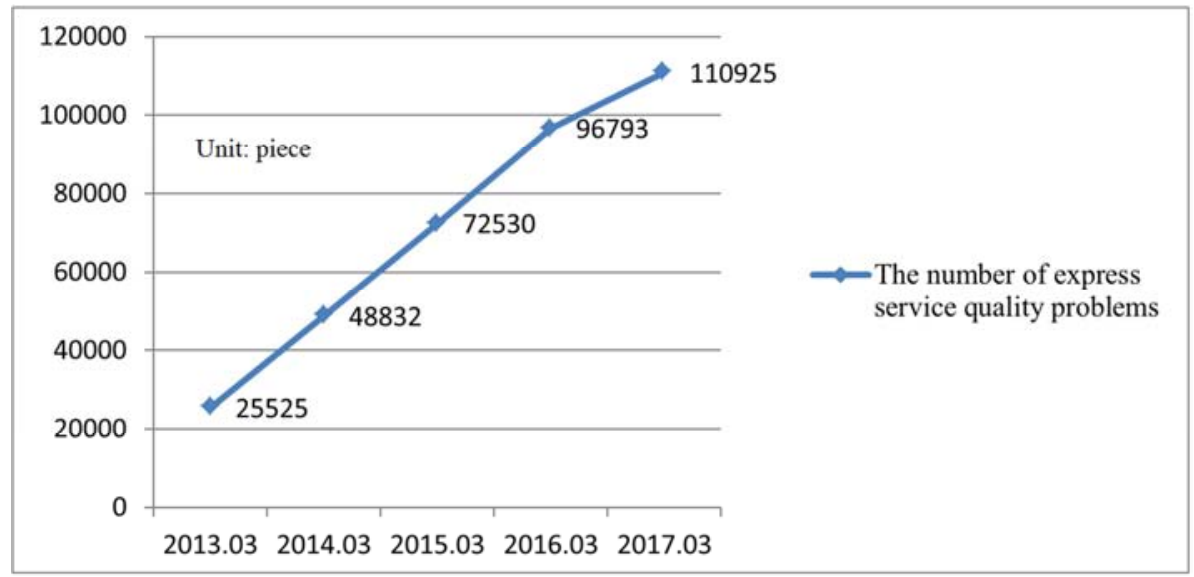

Source: National Post Office Complaint Official Website

Figure 3. 2013.03-2017.03 Express service quality problems.

Figure 3 is from the "12305" State Post Bureau of the official website to collect 2013.03-2017.03 five years of data, analysis of the line graph can be obtained, 2013-2017 China's express service quality problems from 25525 to 110925 pieces, and the increase in the rate of the general show the trend of increasing year by year, indicating that the five-year courier service quality has not been improved and resolved, combined with the five years of express traffic continues to grow, it can see that there is still a lot of growth behind the rapid growth of the service quality problems, many companies how to improve the quality of courier services as an important issue to solve the problem. Many research scholars have also carried out a lot of research and analysis on the quality of express service.

Based on the Kano model, fan Lei, and so on, on the basis of analysis and measurement, proposed a series of measures to improve the quality of express service, such as identifying key service quality, based on the individual demand of customers, expanding the express service line. [1] Yuan Jun based on the
PDCA cycle, through several delivery, customer service, information system and other aspects of the analysis, thus obtains the specific measures for improvement of express company. [2] Yu Baoqin, and other integrated application of PZB model, two stage QFD and fuzzy set theory, proposed a new method of express service quality improvement. [3] Wang Hongwei, and so on take the massive on-line consumer commentary as the data, uses the emotion analysis technology, proposes one kind of express service quality evaluation method. [4] Meng Qingliang, and so on, through the integration of improved Kano model and IPA analysis method, constructs the express service quality detection process model, and determines the priority of the promotion service quality factor promotion. [5] Cao Xia described in the SERVQUAL model of service quality evaluation scale on the basis of the analysis of online shopping courier express delivery price, poor timeliness confusion caused by courier service price satisfaction is low, privacy protection is poor, "online shopping" express complaint rate is high, the paper puts 
forward countermeasures to improve the quality of domestic express enterprises. [6]

Based on the above study, using the evaluation model and fuzzy theory to analyze the influence factors of express service quality too numerous to mention, scholars have done a lot of research, have recognized the importance of improving the quality of service delivery, but there is still a need to add one place, in terms of research subjects, most research has been for a courier companies several aspects of research, less on the overall process improvement of express service quality, so as to study about how to improve the quality of service delivery process and is not comprehensive enough, second, in terms of research methods, in the existing literature by establishing mathematical model and statistical analysis, and the typical case study of express enterprises in the application of Six Sigma less.

Therefore, this paper based on the analysis of Six Sigma Define Measure Analyze Improve Control (DMAIC) process, using the case study method, selection of improved tools in the application of lean and six sigma enterprise, put forward the improvement strategies and control methods of the whole process corresponding to the use of Six Sigma improvement Chinese courier companies to provide guidance.

\section{DMAIC Process}

In the entire business process, six sigma refers to per million opportunities how many defects or mistakes, these defects or errors including the product itself and the production process, packaging, transportation, delivery, force majeure. Six Sigma requires companies to maximize their customer satisfaction by less than 3.4 defects per million opportunities throughout the process. Through the reduction of defects and ineffective operation, the short-term financial performance of enterprises will be increased, shorten the cycle time, improve service quality, reduce costs and improve customer satisfaction. In the Six Sigma development process, lean thinking is also integrated into six sigma improvement methods. Specifically, the lean tools are integrated into the DMAIC process, with the main points of its activities and the main tools shown in figure 4.

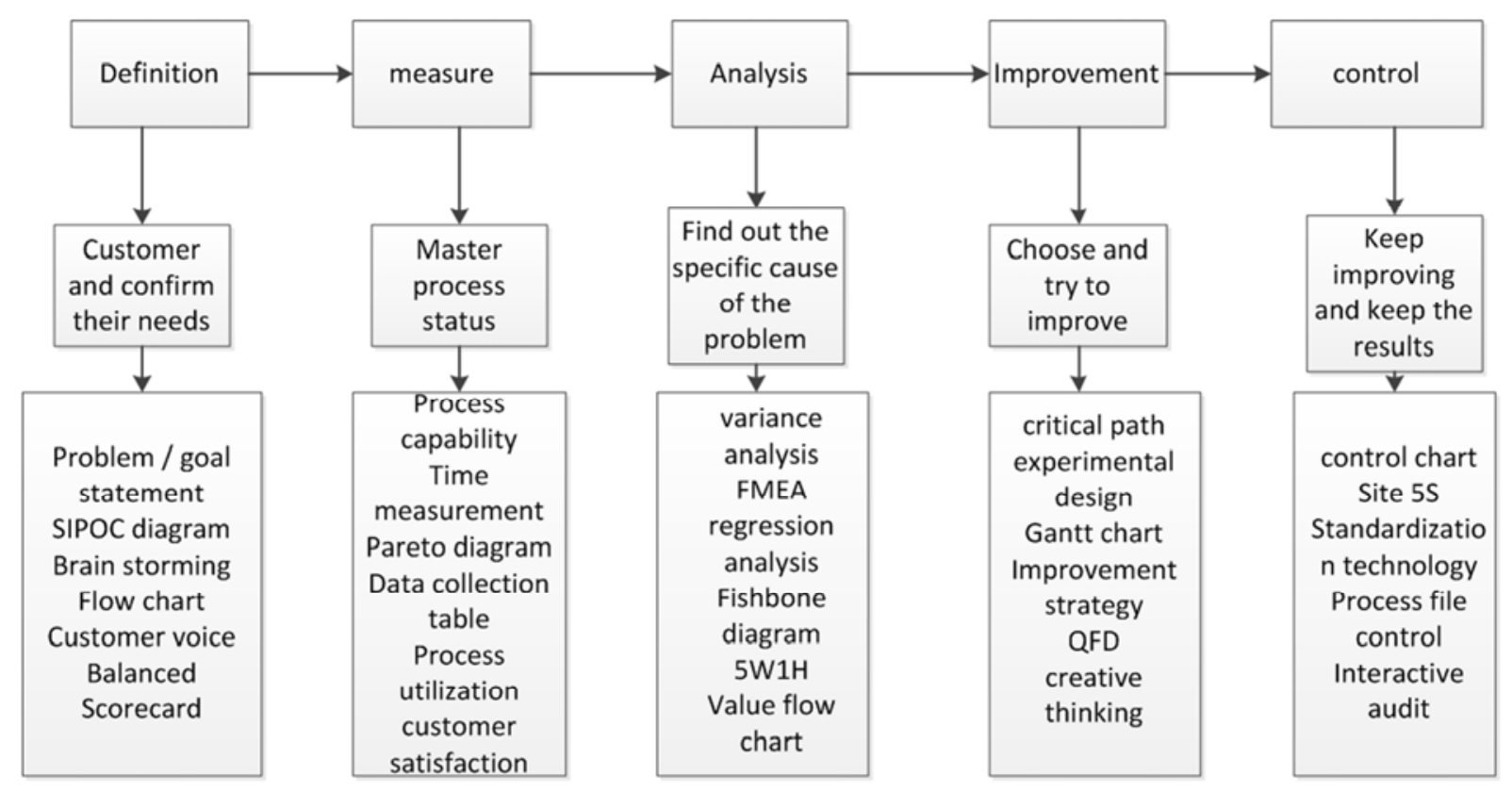

Figure 4. The objectives and main tools of each phase of the DMAIC process.

The key to the success of the Six Sigma implementation is implementation. Therefore, to fully understand and grasp the Six Sigma implementation steps is very important, in general, enterprises in implementing Six Sigma should be divided into five stages to implement, namely (DMAIC process), define the phase measuring phase, analysis phase, improvement stage, control stage. [7] The DMAIC process is divided into the following steps, as shown in figure 2, for each stage, purpose, and main tool of the DMAIC process.

The first step is to define. The important task of defining a phase is to identify the most important roles in any process: the customer, and identify the requirements. Listen to the voice of the customer, the problem/goal statement, do business flow chart, in order to understand and identify the key quality characteristics (CTQ), so as to clearly understand the key point, need to deal with the improvement goal, group work.

The second step is to measure. The important work in the measurement phase is to collect data, make the corresponding data map, calculate the sigma level of the enterprise service quality, and provide the basis for the cause analysis of the problem.

The third step is to analysis. The correct use of tools, can use simple tools to find the root cause of the problem.

The fourth step is to improve. The key steps of DMAIC are to solve the corresponding problems through this step, propose improvement strategy and improve continuously.

The fifth step is to control. Track and evaluate the improvement effect of the previous four stages. According to 
the difference between the expected effect, the error prevention method should be formulated at the same time, and the control measures must be documented.

This paper intends to use the SIPOC diagram tool in the definition stage to do the express business flow chart. In the measurement stage, the Pareto chart and the sigma measurement and analysis tool are used to determine the level of the courier enterprise. At the analysis stage, the fishbone tool is used to find the express business service Quality of the root causes of the problem, in the improvement phase using the service blueprint, site $6 \mathrm{~S}$ and improve the strategy tool to solve the corresponding problems in the control phase using anti-error measures tools to correct the improvement effect, to improve the quality of service delivery business goals.

\section{Express Application of DMAIC Process Case Study}

\subsection{Project Background}

RFD was founded in 2008, is a professional management of the last kilometer distribution of wholly-owned enterprises, opened in 2012 courier business, with the increase in business volume, RFD companies are facing the same problems just set foot in the courier business: poor delivery service attitude, The delay rate is high, the loss is short, the damage rate is high, the service attitude is bad and so on. Although it has long been engaged in the last kilometer distribution of B2C, it has its own hardware scale and software scale support, but these problems still have not been significantly improved, increased rather than decreased the phenomenon still occurs frequently.

The service tenet of RFD company is "service has a starting point, satisfaction has no end". Customer satisfaction as the highest standards, focusing on the introduction of new management ideas and management technology company, so they used the Six Sigma of DMAIC method to solve the problem of express service quality.

\subsection{Project Improvement Process}

\subsubsection{Define the Stage}

At present, the quality of express delivery services, there are delivery services, express delays, loss of short, damaged, receiving and receiving services and other major issues, resulting in the overall quality of the express delivery service is not high, therefore, need to deal with the key points in the delivery service, express The key quality characteristics of improving the service quality of RFD express delivery business are to reduce the probability of occurrence of these five major problems. The improvement method of express service quality is Six Sigma, Some express business service management flow chart, to improve the quality of courier services, improve customer satisfaction with the courier service is a significant effect. RFD Express Enterprise Service Process SIPOC diagram shown in Figure 5.

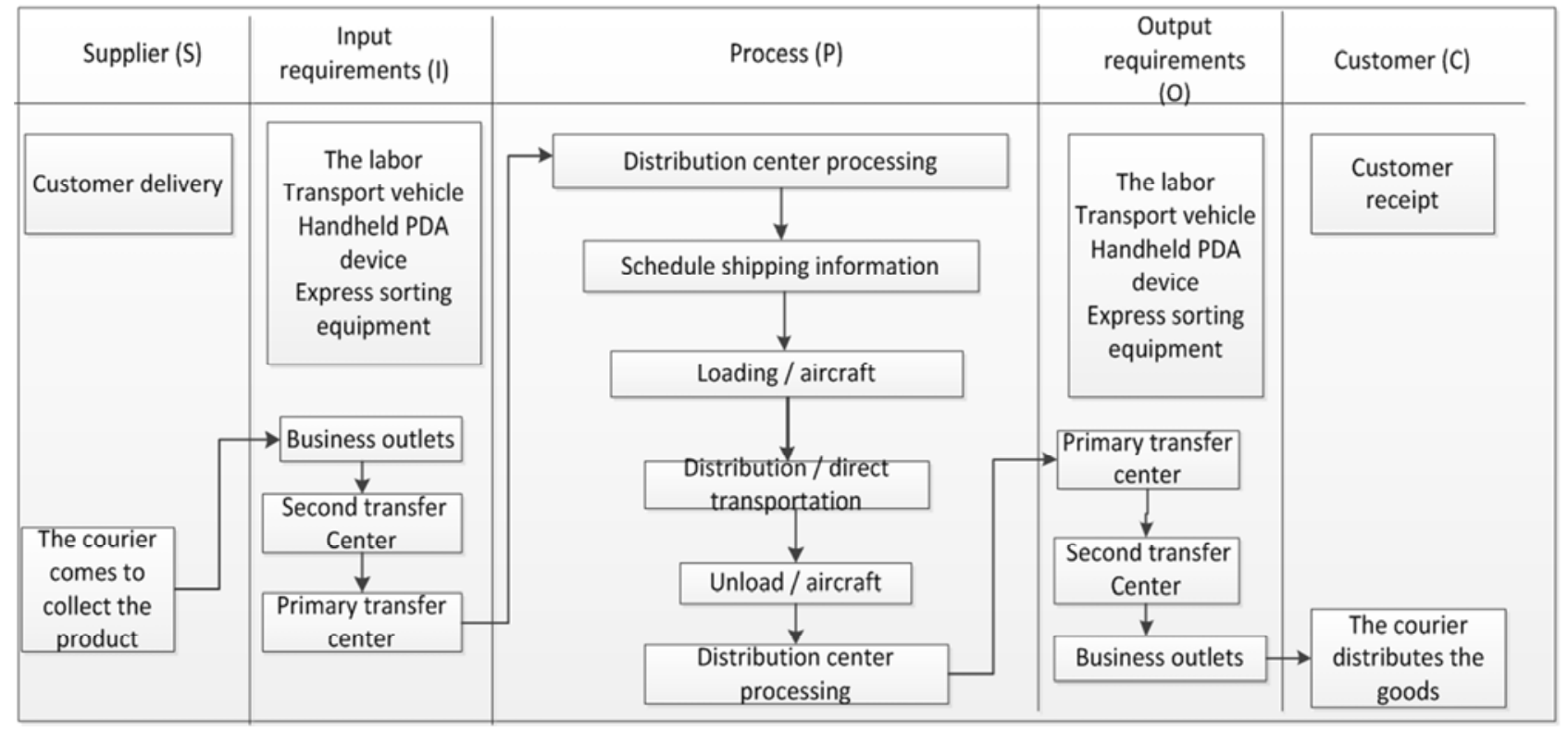

Figure 5. RFD Express Enterprise Service Process SIPOC Figure.

\subsubsection{Measurement Phase}

Around the RFD company express delay rate, loss of short rate, damage rate, delivery service non-positive rate, non-positive rate of delivery service (it will accept the value range of customers as a well-known norms) these five categories of indicators to collect data, The total number of collected questionnaires to meet the statistical requirements of the standard, and the questionnaire quality is low, then through the State Post Bureau official website to start RFD company data collection, in view of RFD Express Enterprise service management system is a month at the beginning of the month to summarize the last month, every three months to make a summary of the collection of the two quarterly courier service quality statistics for comparison, taking into account the two quarters of the delivery volume to be accounted for The annual express volume is the largest, only a statistically 
representative, selected in the third quarter of 2010 and the analysis, as shown in Figure 6 and Figure 7. fourth quarter of the courier service quality statistics for

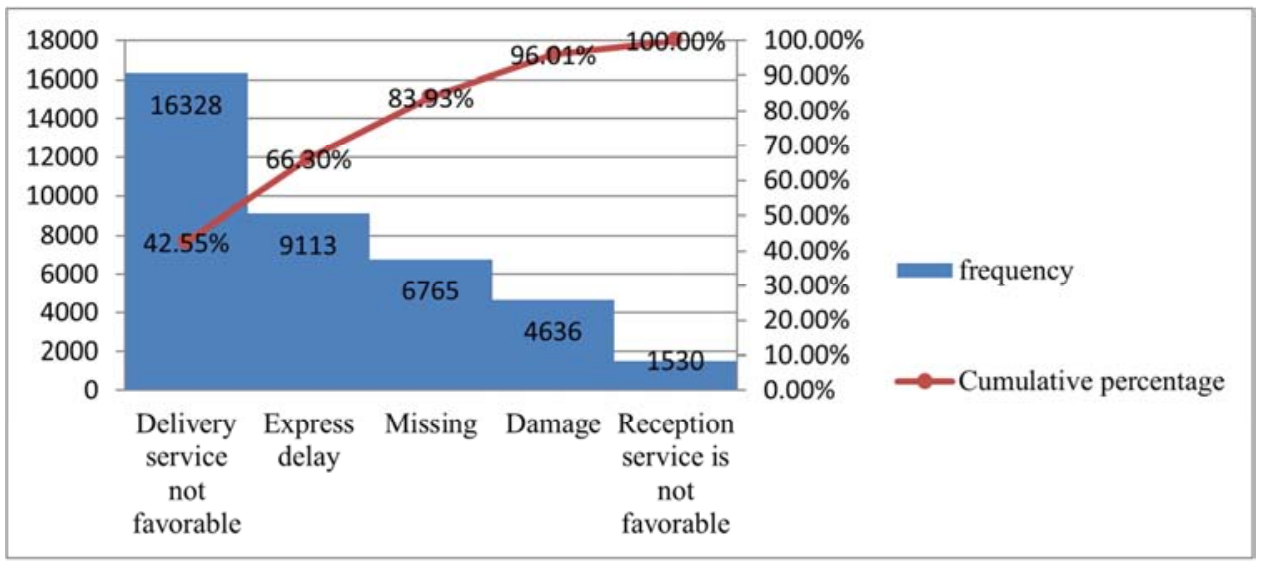

Figure 6. Express service quality in the third quarter of 2016 Pareto chart.

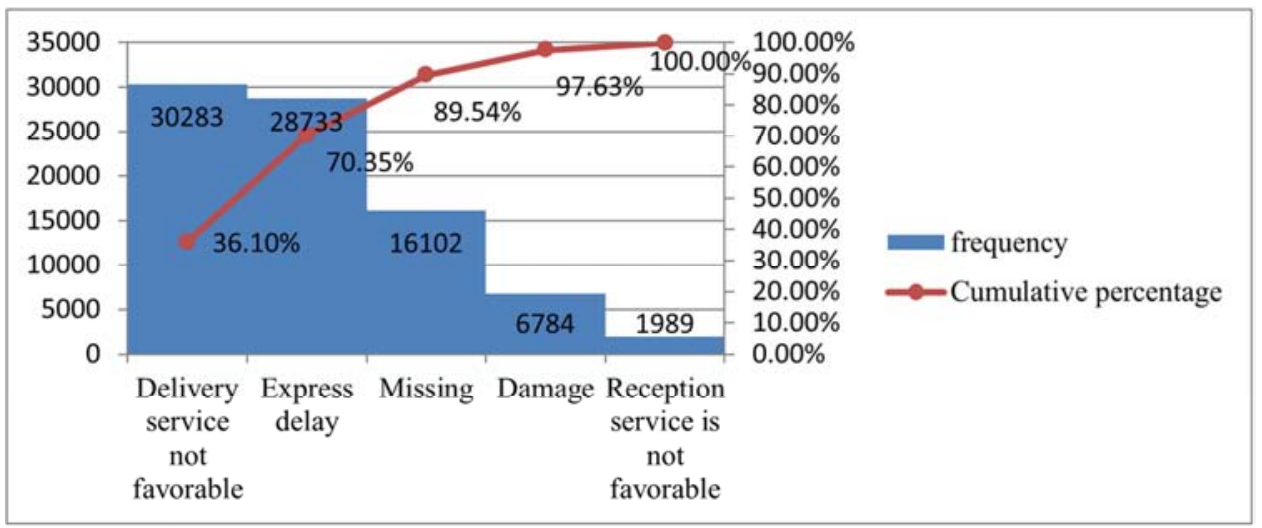

Figure 7. The fourth quarter of 2016, the quality of service delivery Pareto chart.

Figure 6 and Figure 7, respectively, in the third quarter of 2016 and the fourth quarter of 2016 RFD courier service quality related to the five major categories of key quality characteristics of the Pareto map, the RFD company courier service quality as a whole The first four of the frequency of the problem, respectively, delivery services, express delays, loss of short, damage, which by the front stage of the proposed five categories of precision issues to delivery services, express delays, lost short, damage these four categories of problems, improve this Four key quality characteristics, can solve the RFD company more than $80 \%$ of the courier service quality.

In the data measurement phase, from the National Post Office 12305 complaints hotline website to provide us with information, these information data in a large number of text comments form, through the emotional analysis technology, [8] the content of these subjective content extraction, analysis, To determine the emotional tendencies of the text comment (praise/derogatory), emotional tendencies for the praise, the consumer satisfaction with a service performance, but words, demoted that consumers dissatisfied with the service expressed through complaints, in accordance with delivery services, express delays, The loss of short and damage to the complaints of these four categories, sorted out a RFD company belongs to the database, the use of SPSS 21.0 statistical tools to sample out 1000 RFD company complaints about the data, the number of delivery service complaints 68 times, express Delay the number of complaints 35 times, lost the number of complaints 17 times, the damage has been 5 times, according to the opportunity defect rate DPO formula:

$\mathrm{DPO}=$ total number of defects $/($ number of products $\times$ chance number $)=(68+35+17+5) /(1000 \times 4)=0.03125$

$$
\mathrm{DPMO}=\mathrm{DPO} \times 10^{\wedge} 6=31250
$$

After the Sigma DPMO formula calculation, the opportunity to come out every million opportunities for 31250 courier service quality complaints, by looking for Six Sigma DPMO table, it can see RFD Express service quality level of about 3.4 Sigma. This means that 6210 to 66800 defects have been generated per million opportunities that will require RFD to make up for 15 to 30 percent of its sales.

\subsubsection{Analysis Phase}

Combined with the express service process and the theoretical considerations, in this case, we use the fish bone chart analysis RFD express service to produce the root causes of defects, as shown in Figure 8. 


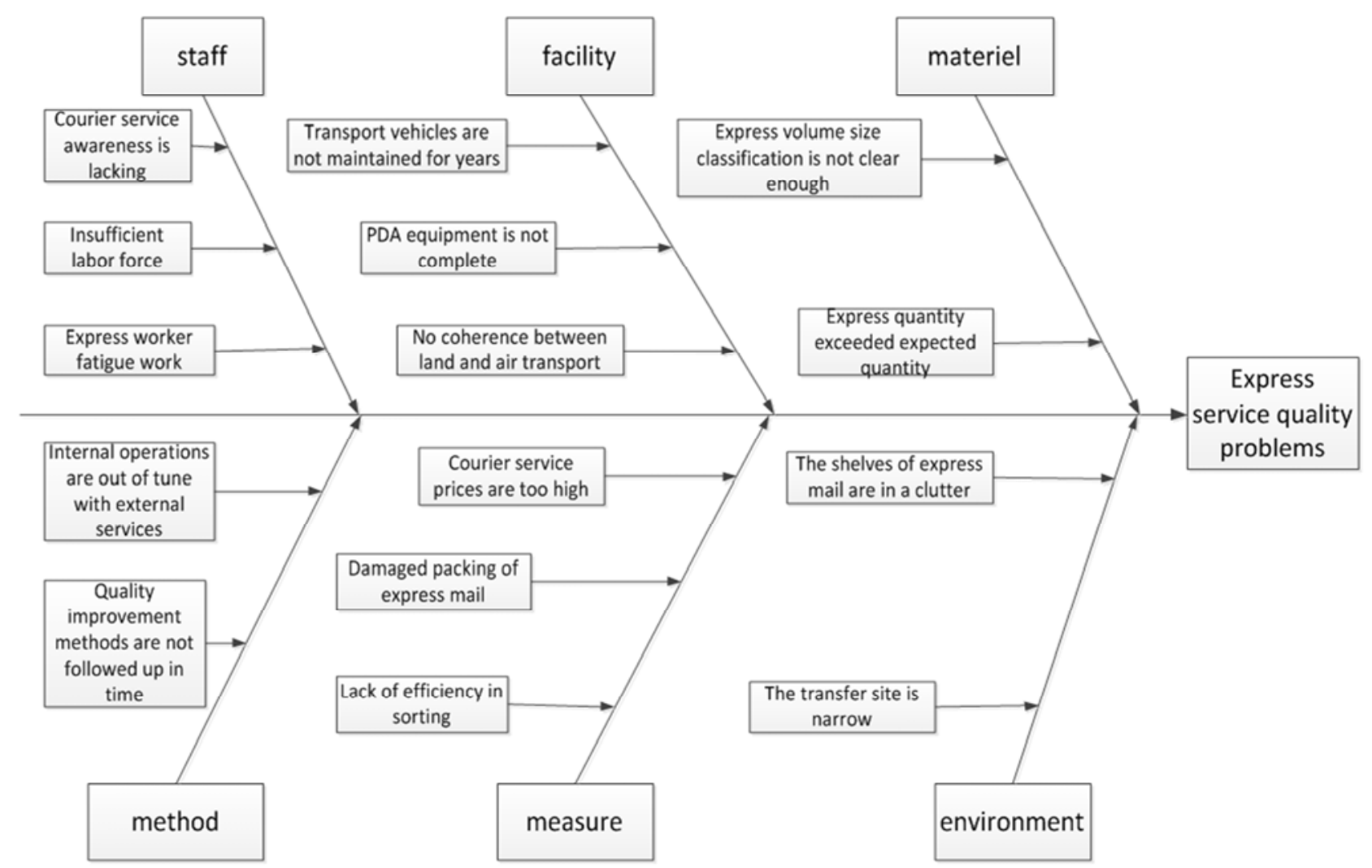

Figure 8. RFD company express service quality analysis of the reasons for fish bone map.

According to the analysis of the influencing factors of express service quality, it is found that the reason of express service quality mainly includes the following aspects: (1) The express volume and weight classification are not clear, and the number of express pieces exceeds the receivable quantity; (2) The transportation vehicle is not maintained year by year, (3) Express service price is too high, express packaging damage, sorting the lack of efficiency; (4) the lack of service, (5) internal operations and external services are not coordinated, quality improvement methods are not timely follow-up.

\subsubsection{Improvement Phase}

In the definition phase, courier services SIPOC flow chart to make RFD company, found that there are many areas for improvement, this paper intends to SIPOC Figure RFD redesigned courier service processes, improve after shown in Figure 9.

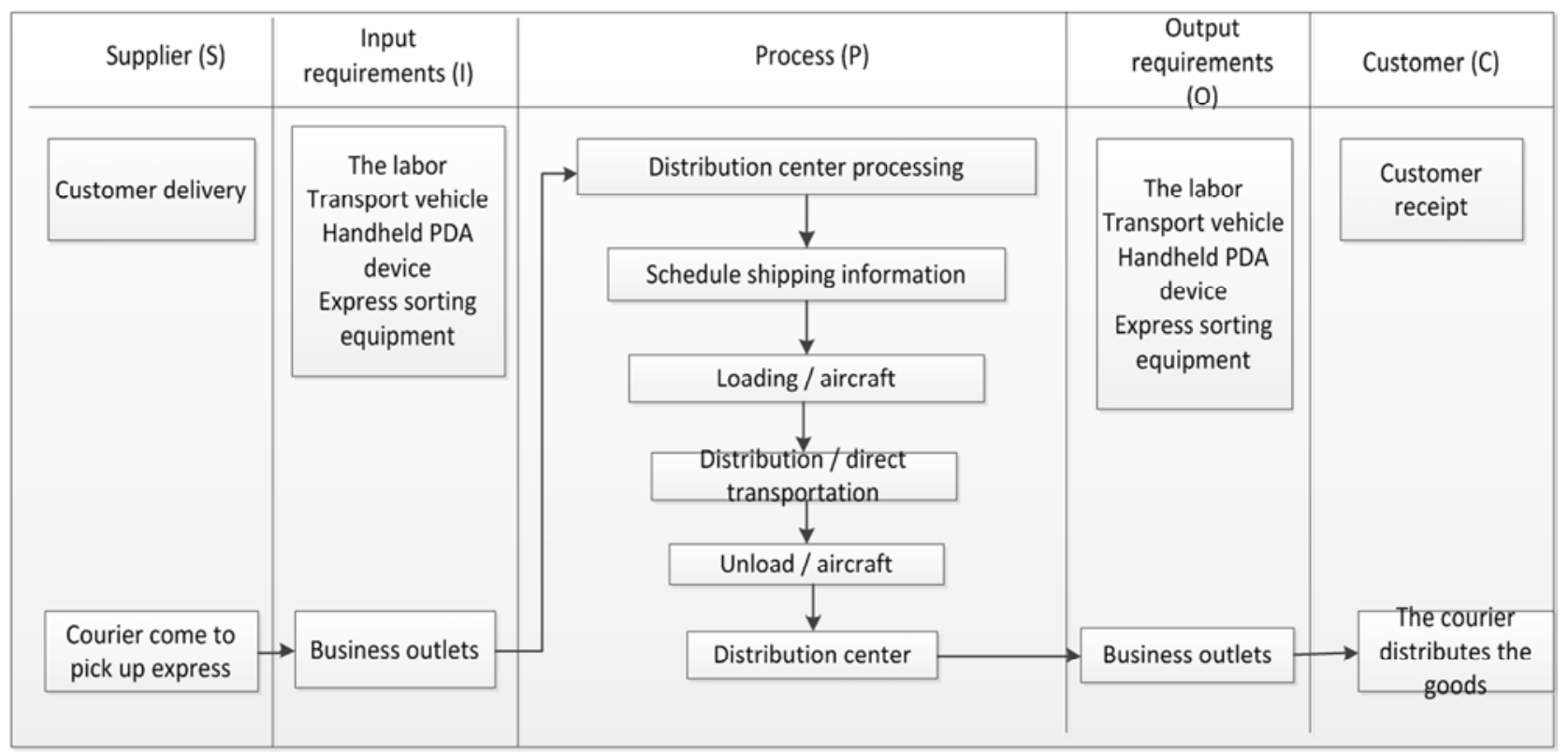

Figure 9. RFD improved express service flow SIPOC diagram. 
Figure 9 shows that, compared to traditional courier service business processes, improved service delivery process by the customer delivery concerns began, destined to be sent through the distribution center outlets, to arrive by post-distribution center handling, transportation outlets and finally to the end of the customer sign. The purpose is to integrate the operational operations in the three-tier transit center and the secondary transfer center into the dispatch center and the dispatch center. In the dispatching and dispatching center, the express mail is sorted and distributed according to the business outlets processing stage, eliminating the need for re-allocation of tertiary and secondary transshipment centers for express mail sorting, transport and distribution for a lot of time and improve operational efficiency, reducing the probability of occurrence of shipment delays.

We put forward the corresponding improvement measures for the main 5M1E analyzed, as follows:

(1) clear express volume and weight classification, to develop solutions to solve the surge program. In the sorting process, in order to improve the sorting efficiency, the express weight is more than $50 \mathrm{~kg}$, the volume is more than $40 \mathrm{~cm} \times$ $60 \mathrm{~cm} \times 100 \mathrm{~cm}$, the assembly is divided into the weight of the express mail, and the tray is used for the assembly, the forklift sorting operation, The express mail to the same location can be concentrated in the tray, forklift trucking on the car, reducing the loading and unloading process in the man-made damage, improve the handling efficiency. The number of express mail mainly from the major electricity business platform orders, such as Alibaba in the double before the big data will be calculated by the day of the transaction volume, the number of orders and the degree of regional consumption,[9] a reasonable allocation of software resources and hardware equipment. In the holiday season and other shopping season before the arrival of the rapid increase in the shipment, RFD Express business should be through the application of large data, you can calculate the number of future electricity providers to the future number of orders to predict the number of express mail will be generated, according to the corresponding The number of express mail, sorting center should be a positive response to the development of appropriate solutions, making the courier business response more ease, more quickly and efficiently meet customer demand for consumption. [10]

(2) strict implementation of transport vehicle maintenance system, improve the land and air transport cooperation mechanism. When the transport vehicle ends the express mail service on the day, the vehicle inspector should accurately record the driver's problems in the running state of the vehicle, the mileage of the vehicle and the fuel consumption, and check the maintenance in time for the vehicle to be scrapped to the relevant departments to do the work of scrapped vehicles. At present, RFD express delivery company is mainly land and air transport mode of transport, land and air transport is mainly air transport, handling fast pieces in the two modes of transport between the convergence, should make the shipment of the transport flight time and truck flight time Match, do that loading and unloading, express unloading from the aircraft, not through the storage of air storage, direct shipment to the train or truck, to land and air transport seamless docking, shorten the transit time, improve transport efficiency.

(3) the increase in labor supply, enhance staff awareness of service quality. Individual organizations within the enterprise service means the customer service staff, middle management, the implementation of responsible persons; external service refers to the individual business department staff, express acceptance staff, line managers and so on. First, the human resources department can express the amount of surge in the period, the temporary employment of full-time pickers, or better use of existing staff, some staff will be transferred to the shortage of staff jobs, relieve other operations part of the effort to reduce sorters due to heavy workload and fatigue; second, the express delivery companies in the RFD external service staff awareness training should be systematic planning, invited experts and scholars in the field of service delivery quality professional training, field operations and research assessment, strengthen supervision and inspection, to improve the skills of workers, so that employees work done high-quality service in less time.

(4) To implement the $6 \mathrm{~S}$ management, optimize the workplace environment. $6 \mathrm{~S}$ management is a $5 \mathrm{~S}$ management innovation, as a good tool to create a good working environment and improve staff literacy. $6 \mathrm{~S}$ is finishing, rectification, cleaning, cleaning, quality, security. [11] 1) finishing. The shuttle sorting sites, transit centers and other places to conduct a comprehensive inspection, including the see and can't see, sorted out to a corner can't see the express mail, found that unnecessary items according to the provisions of the deal. 2) tification. Involving forklift, transportation and a series of activities required trailers, forklifts, shelves and other equipment, must be in accordance with the scientific layout, neatly placed, to be identified, to achieve access to fast standards. 3) ing. Express the workplace can see and see the place are easy to produce packaging waste and staff littering litter, the establishment of a clean area, and staff performance linked to ensure that the workplace clean and neat environment. 4) n. Will be finishing, rectification, cleaning into the workplace must comply with the rules, so that the results of the above $3 \mathrm{~S}$ in the end, so that the maintenance of a clean working environment awareness into the hearts of each employee. 5) racy. Regular staff training and assessment of the company's internal rules and regulations, self-reflection need to improve the place, and establish a sense of care for everyone clean working environment, so that the workplace environment to maintain a high degree of cleanliness. 6) e. Regular inspection of the workplace safety fire facilities available in the field paste the visual logo to prevent accidents and accidents, the establishment of workplace safety management mechanism to prevent combustible, explosive and other items into the scene, improve the safety awareness.

(5) to establish a complete courier service quality evaluation system to speed up the transformation and upgrading of infrastructure. RFD measure the actual value of 
the price courier service, package damage rate and sorting speed of express delivery companies, to be a dialectical view of the gap between standard or industry standard measurements and business settings, realistically improve the quality of service delivery, establish a complete set service quality evaluation system selected scientific indicators, accurate and reasonable assessment, in order to narrow the gap between the top managers of the enterprise service quality perception and the actual user experience. Enterprises should vigorously capital market to increase infrastructure construction, and to seek transformation and upgrading. By landing the capital market, the industry raised funds into the construction of aircraft, transport vehicles, cold transport equipment, intelligent sorting equipment, information systems and transit venues, the enhanced network control, can better safeguard the overall level of quality of service delivery.

(6) the establishment of internal operations and external service coordination mechanism to enhance the overall quality of service enterprises. In order to improve the quality of express service itself, the focus is to combine the internal and external services of enterprises to make a systematic scientific planning, regular professional training, establish a unique brand culture, create a strong sense of honor, enhance corporate centripetal force The Based on this, courier companies must first establish a coordination mechanism between internal operations and external services, service commitments to achieve or make customer satisfaction is one of the important requirements; Second, courier companies should pay attention to innovation, carry forward their own strengths and strengths, The industry in this area of insufficient enterprises to provide professional and reliable services, to differentiate the way to promote the formation of unique brand concept; In addition, RFD express delivery business in the design courier service, courier service should consider the whole process of all the key points of experience, with the help of services Blueprint and other tools,[12] from the courier service tangible display, customer behavior to the front desk service employee behavior, background service employee behavior and internal support activities. The service blueprint tool is based on the existing service system of the express operation and the external service, which is weak and the system efficiency. The improvement scheme is put forward to improve the efficiency of the whole express delivery service system, to prevent the unnecessary customer service experience and property loss, Improve the overall quality of service delivery company. The RFD Express Enterprise Service Blueprint is shown in Figure 10.

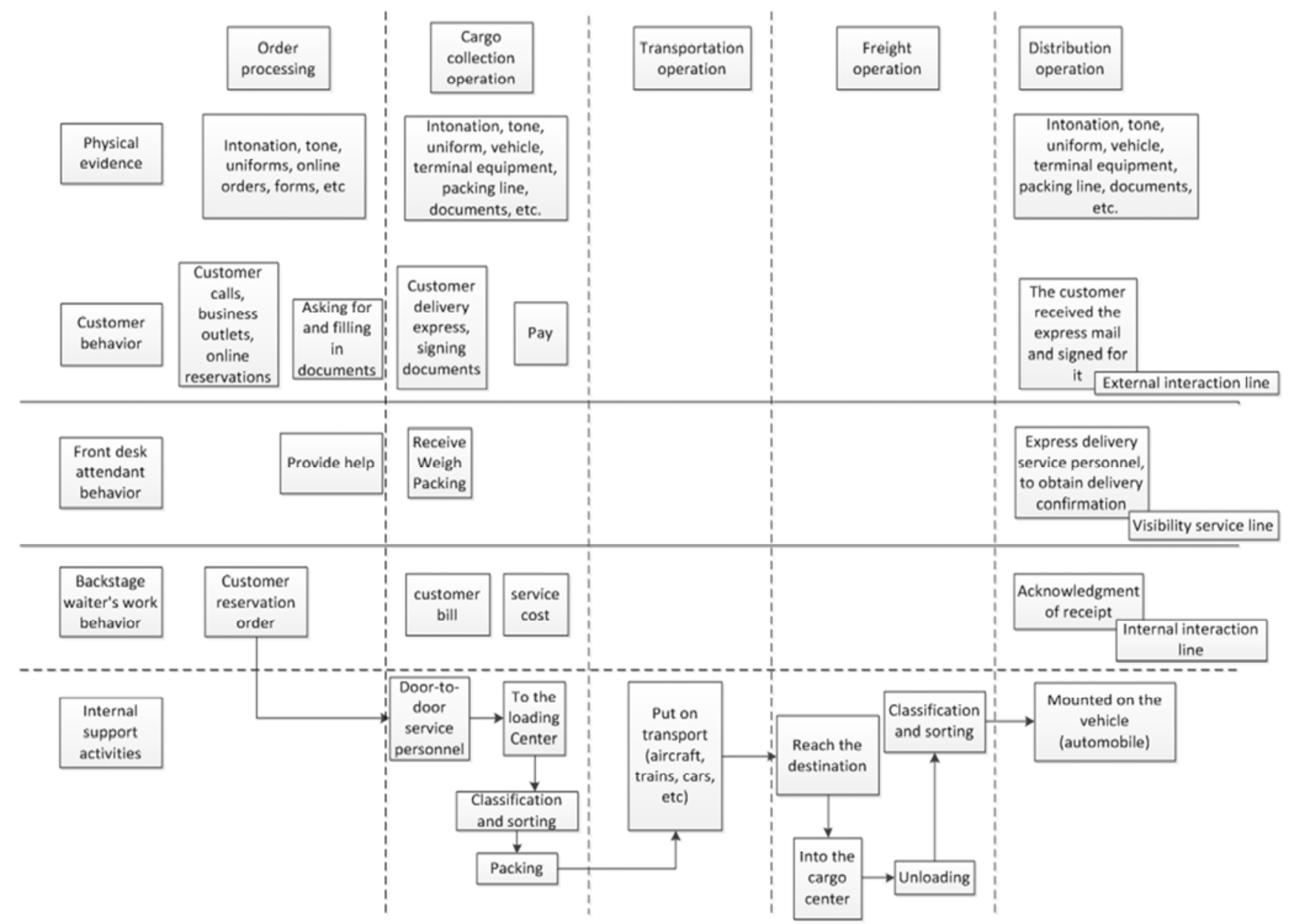

Figure 10. Express business service blueprint. 


\subsubsection{Control Phase}

In view of the improvement measures in the implementation process, there will be a series of errors, put forward the corresponding anti-error method, anti-error method is as follows:

(1) re-measuring system analysis

Especially for the key quality characteristics of input factors $\mathrm{X}$ (such as delivery services, express delays and missing short, etc.) in the application of measurement system analysis technology to determine whether its measurement system fluctuations in the courier service quality evaluation system to meet the test needs, or adjust accordingly $\mathrm{X}$ value range, in addition to the need for key quality characteristics of the measurement system analysis, because the improvement, the process of the smaller fluctuations in the process tends to be stable, the original measurement system can't distinguish between process fluctuations, so the need to re-measurement System analysis.

(2) re-evaluate the process capacity of the process of interest

If necessary, to establish the control chart, the SPC technology for real-time control of the express service process characteristics, identify the special causes of fluctuations in process performance, the implementation of measures to reduce the volatility, recalculate the express service process capability and maintain the improvement results.

(3) enact and strictly enforce flow control plans

Document changes to process improvements or process improvements, develop rigorous process control plans, and incorporate them into express delivery service quality management systems.

Application of anti-error method to achieve the purpose of continuous improvement, control results, and by measuring the actual effect of the improvement measures compared with the expected results, according to the difference between the two timely summary, and take appropriate measures to improve the results of control in a reasonable range. [13-14] And comprehensively understand and implement the Six Sigma implementation steps to ensure the continuous and steady improvement of the quality of express service. The construction of Six Sigma to improve the quality of express delivery service in five stages of definition, measurement, analysis, improvement and control.

\section{Conclusions}

Under current severe market competition, express enterprises are paying more and more attention to improving the quality of express delivery service. On the research object, most previous studies have mainly studied several aspects of the express business, but there is less attention to study the whole process of improving the quality of the courier service, while ignoring how to improve the quality of courier service. It turns out that the problems of service quality of express delivery enterprise can't be effectively reduced.

Based on the present situation, this paper aims to explore the service quality of express courier service, analyzes the service quality of courier service, redesigns the process of express delivery service business and puts forward the improvement strategy and the whole process control method by means of a real case. Because of the limited number of questionnaire respondents and the low rate of questionnaire recovery during the questionnaire survey, some limitations exist in the analysis of the results. So it has difficulty in the validation verification of the DMAIC method in express enterprises, which should be regarded as the future research directions.

\section{Fund Project}

National key research and development plan "research and application of logistics service certification scheme" (2016YFF0204105-1)

\section{References}

[1] Fan Lei. Express delivery service quality improvement for customer satisfaction [J]. Journal of Jiangsu University of Science and Technology (Social science edition), 2016, (16): 103-107.

[2] Yuan Jun. S express delivery service quality improvement [J]. Logistics Engineering and Management, 2015, (6): 124-125.

[3] Yu baoqin. Based on the two-phase QFD method of express service quality improvement [J]. Statistics and Decision, 2013, (8): 39-41.

[4] Wang Hongwei. Evaluation of express service quality based on online review sentiment analysis [J]. Journal of Beijing University of Technology, 2017, (3): 402-412.

[5] Meng Qingliang. Integrated Kano model and IPA analysis method for express service quality detection [J]. Industrial Engineering and Management, 2014, (2): 75-80.

[6] Cao Xia. Research on the quality evaluation system of online shopping express service based on SERVQUAL model [J]. Railway Transportation and Economics, 2015, (8): 93-98.

[7] Philip Crosby. Cut the cost of quality [M]. Beijing: Renmin University of China press, 2006.

[8] Syed, Akib, Anwar, Hridoy. Localized twitter mining using sentiment analysis [J]. Springer Berlin Heidelberg, 2015, 2 (8): $1-19$.

[9] Lei Minglong. Research on shopping behavior based on alibaba's big data [J]. Internet of Things Technology, 2016, (5): 57-60.

[10] Yang Kai. Research on the staffing model of picking centers under the fluctuation of express quantity [D]. Dalian University of Technology, 2013.

[11] Sun Guang. Study on methods of improving the effectiveness of $6 \mathrm{~S}$ management in logistics warehousing enterprises [J]. Logistics Engineering and Management, 2010, (12): 35-37.

[12] Le Xiongping. Based on 5M1E analysis to improve the quality of logistics in the logistics industry [J]. Railway Transport and Economy, 2016, (8): 66-70. 
[13] Sun Mengjie. B2C Analysis of the feasibility of logistics unified delivery model under electronic commerce [J]. Logistics Engineering and Management, 2012, (12): 16-18.
[14] Zhang Yang. Quality improvement of electricity supplier logistics service based on Six Sigma [J]. Logistics Engineering and Management, 2016, (2): 25-27. 